\title{
Hepatitis C Virus Subtypes Novel 6g-Related Subtype and 6w Could Be Indigenous in Southern Taiwan with Characteristic Geographic Distribution
}

\author{
Hung-Da Tung ${ }^{1} \mathbb{D}$, Pei-Lun Lee ${ }^{1}$, Jyh-Jou Chen ${ }^{1, *} \mathbb{C}$, Hsing-Tao Kuo ${ }^{2} \mathbb{D}$, Ming-Jen Sheu ${ }^{2}$, Chun-Ta Cheng ${ }^{1}$, \\ Tang-Wei Chuang ${ }^{1}$, Hsu-Ju Kao ${ }^{1}$, Yu-Hsun $\mathrm{Wu}^{1}{ }^{1}$, Mai-Gio Pang ${ }^{1}$, Cheng-Heng Lin ${ }^{1}$, Chia-Yi Hou ${ }^{3}$, \\ Hsin-Hua Tsai ${ }^{4}$, Li-Ching $\mathrm{Wu}^{4,5}$ and Chuan Lee ${ }^{6}$
}

check for updates

Citation: Tung, H.-D.; Lee, P.-L.; Chen, J.-J.; Kuo, H.-T.; Sheu, M.-J.; Cheng, C.-T.; Chuang, T.-W.; Kao, H.-J.; Wu, Y.-H.; Pang, M.-G.; et al. Hepatitis C Virus Subtypes Novel 6g-Related Subtype and 6w Could Be Indigenous in Southern Taiwan with Characteristic Geographic Distribution. Viruses 2021, 13, 1316. https://doi.org/10.3390/v13071316

Academic Editor: Kei Fujiwara

Received: 30 April 2021

Accepted: 4 July 2021

Published: 7 July 2021

Publisher's Note: MDPI stays neutral with regard to jurisdictional claims in published maps and institutional affiliations.

Copyright: (c) 2021 by the authors. Licensee MDPI, Basel, Switzerland. This article is an open access article distributed under the terms and conditions of the Creative Commons Attribution (CC BY) license (https:// creativecommons.org/licenses/by/ $4.0 /)$.
1 Division of Gastroenterology and Hepatology, Department of Internal Medicine, Chi-Mei Medical Center, Liouying, Tainan 73657, Taiwan; d931102@mail.chimei.org.tw (H.-D.T.); peilun57@yahoo.com.tw (P.-L.L.); moon486058@yahoo.com.tw (C.-T.C.); hoffman.i323@msa.hinet.net (T.-W.C.); ju928@hotmail.com (H.-J.K.); B101091076@tmu.edu.tw (Y.-H.W.); pangmaigio@gmail.com (M.-G.P.); skipclown@hotmail.com (C.-H.L.)

2 Division of Gastroenterology and Hepatology, Department of Internal Medicine, Chi-Mei Medical Center, Yongkang, Tainan 71004, Taiwan; kuohsu2003@yahoo.com.tw (H.-T.K.); hmj@mail.chimei.org.tw (M.-J.S.)

3 Department of Clinical Pathology, Chi-Mei Medical Center, Liouying, Tainan 73657, Taiwan; 960360@mail.chimei.org.tw

4 Department of Clinical Pathology, Chi-Mei Medical Center, Yongkang, Tainan 71004, Taiwan; livelychord@gmail.com (H.-H.T.); 540012@mail.chimei.org.tw (L.-C.W.)

5 Institute of Biomedical Science, National Sun Yat-sen University, Kaohsiung 804201, Taiwan

6 Division of Gastroenterology and Hepatology, Department of Internal Medicine, Chi-Mei Hospital, Chiali, Tainan 72263, Taiwan; chuanli30@yahoo.com.tw

* Correspondence: jjchen@mail.chimei.org.tw

\begin{abstract}
Hepatitis C virus (HCV) genotype (GT) 6 is the most genetically diverse GT and mainly distributed in Southeast Asia and south China but not Taiwan. Earlier studies showed the major HCV GTs in Taiwan were GT $1 \mathrm{~b}$ and 2 with very rare GT 6 except in injection drug users (IDUs), and subtype $6 a$ is the main GT 6 subtype among IDUs. Recently, we reported a much higher prevalence (18.3\%) of GT 6 in Tainan City, southern Taiwan. This study was designed to clarify the subtypes of GT 6 in this endemic area. A total of 3022 (1343 men and 1679 women) HCV viremic patients were enrolled. Subtypes of GT 6 were determined by sequencing of core/E1 and nonstructural protein 5B in 322 of 518 GT 6 patients. The overall GT 6 prevalence rate was $17.1 \%(518 / 3022)$, with higher prevalence districts $(>25 \%$ ) located in northern Tainan. A novel $6 \mathrm{~g}$-related subtype is the most prevalent subtype $(81.0 \%)$, followed by $6 \mathrm{w}(10.8 \%), 6 \mathrm{a}(7.5 \%)$, and $6 \mathrm{n}(0.7 \%)$. The high GT 6 prevalence in Tainan was mainly due to a novel $6 \mathrm{~g}$-related subtype and $6 \mathrm{w}$. These two subtypes could be indigenous in Tainan with characteristic geographic distribution.
\end{abstract}

Keywords: hepatitis $C$ virus; genotype; injection drug user; phylogenetic analysis

\section{Introduction}

Determination of hepatitis C virus (HCV) genotypes (GTs) and subtypes is crucial in the understanding of viral evolution, transmission, epidemiology, and treatments selection. Even in the era of interferon-free, pan-genotypic direct acting antivirals (DAAs), some rare subtypes might harbor intrinsic resistance to DAAs [1]. The efficacy of pan-genotypic DDAs might be suboptimal for these local endemic subtypes, as clinical trials covered mainly the global epidemic genotypes/subtypes only [1-4]. Moreover, the geographic differences in distribution of HCV genotypes and subtypes could reflect the epidemiological history of the virus [5]. Understanding these local endemic subtypes could help to improve public health strategies to prevent further transmission and spreading. HCV GT 6 is the most genetically diverse genotype and is mainly distributed in Southeast Asia, southern China, or immigrants from these area [6-10]. Although Taiwan is an HCV endemic 
country with an overall prevalence of positive HCV antibody (anti-HCV) of 3-5\% in adults, the major prevalent subtypes are $1 \mathrm{~b}$ and 2a [11-15]. HCV GT 6 infection was seldom reported from Taiwan except among injection drug users (IDUs) and patients with human immunodeficiency virus (HIV) infection, and the major GT 6 subtypes were $6 \mathrm{a}, 6 \mathrm{k}$, and 6 n $[16,17]$. We recently reported an unexpected high prevalence $(18.3 \%)$ of HCV GT 6 in Tainan City, with remarkably geographic restriction between two rivers. To clarify the epidemiology of this unique HCV GT in southern Taiwan as a local endemic disease and geographic variation of GT 6 subtypes, we further determined the subtypes of GT 6 and analyzed their distribution in Tainan City.

\section{Materials and Methods}

\subsection{Study Population}

From 1 March 2016 to 28 February 2019, a total of 3339 patients with HCV viremia who were followed up at Chi Mei medical system, including Yongkang, Liouying, and Chiali (Jiali, in Figures 1 and 2) campuses for reimbursement of DAAs treatment were enrolled, including 317 patients who are not residents of Tainan city (Kaohsiung City and Chiayi City/County, at south and north of Tainan). There were 3022 (1343 men and 1679 women, mean age, $64.6 \pm 12.4$ years) patients who live in 37 districts of Tainan City. We excluded the Lonqgi district, for only one patient was registered in our database. The definition of patients living district was according to patients' chart records.
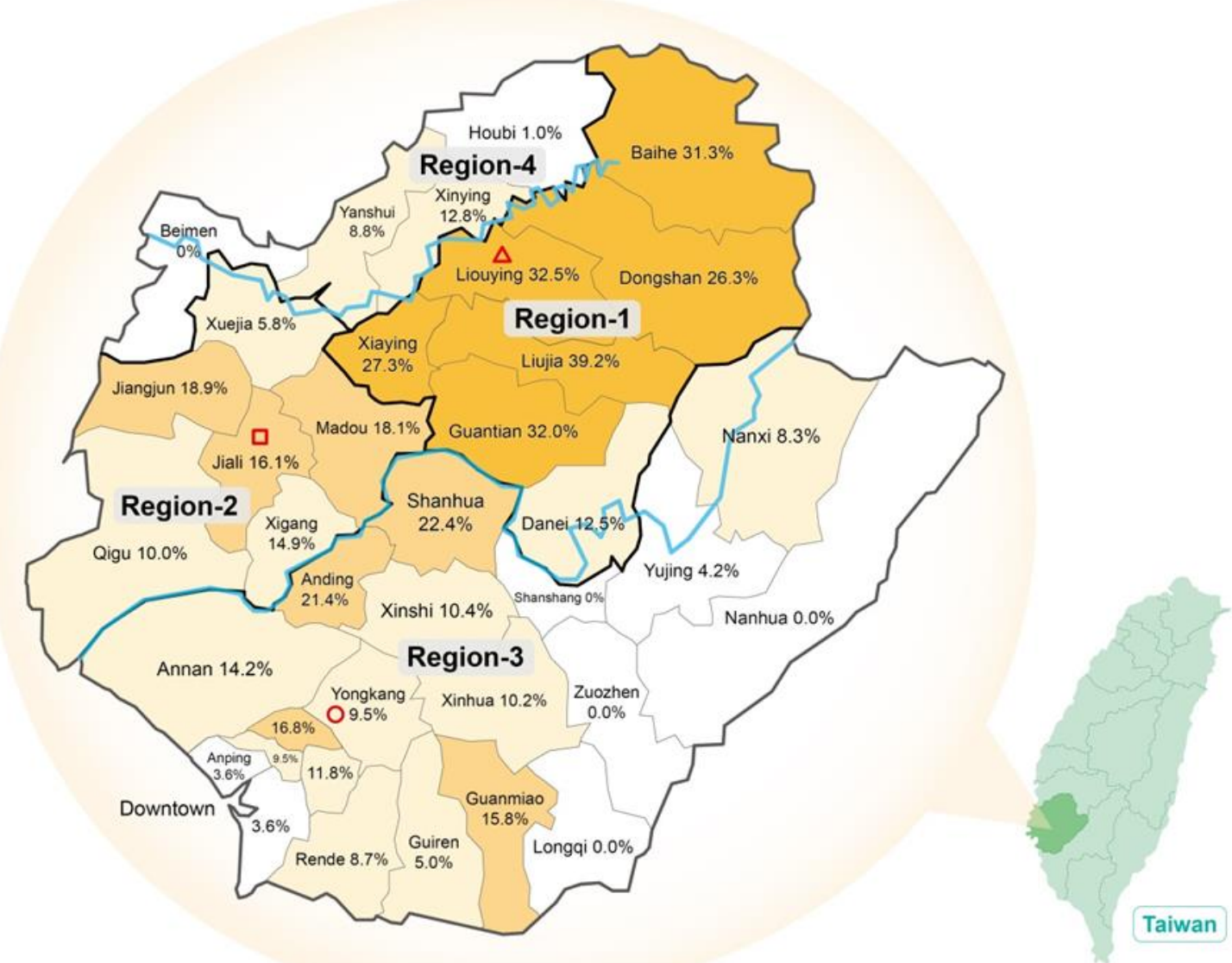

Figure 1. Prevalence rates of HCV GT 6 in each district of Tainan. (Blue lines: two main rivers, top: Jishui; middle: Zengwen; red hollow circle, triangle and square: locations of three campuses). 


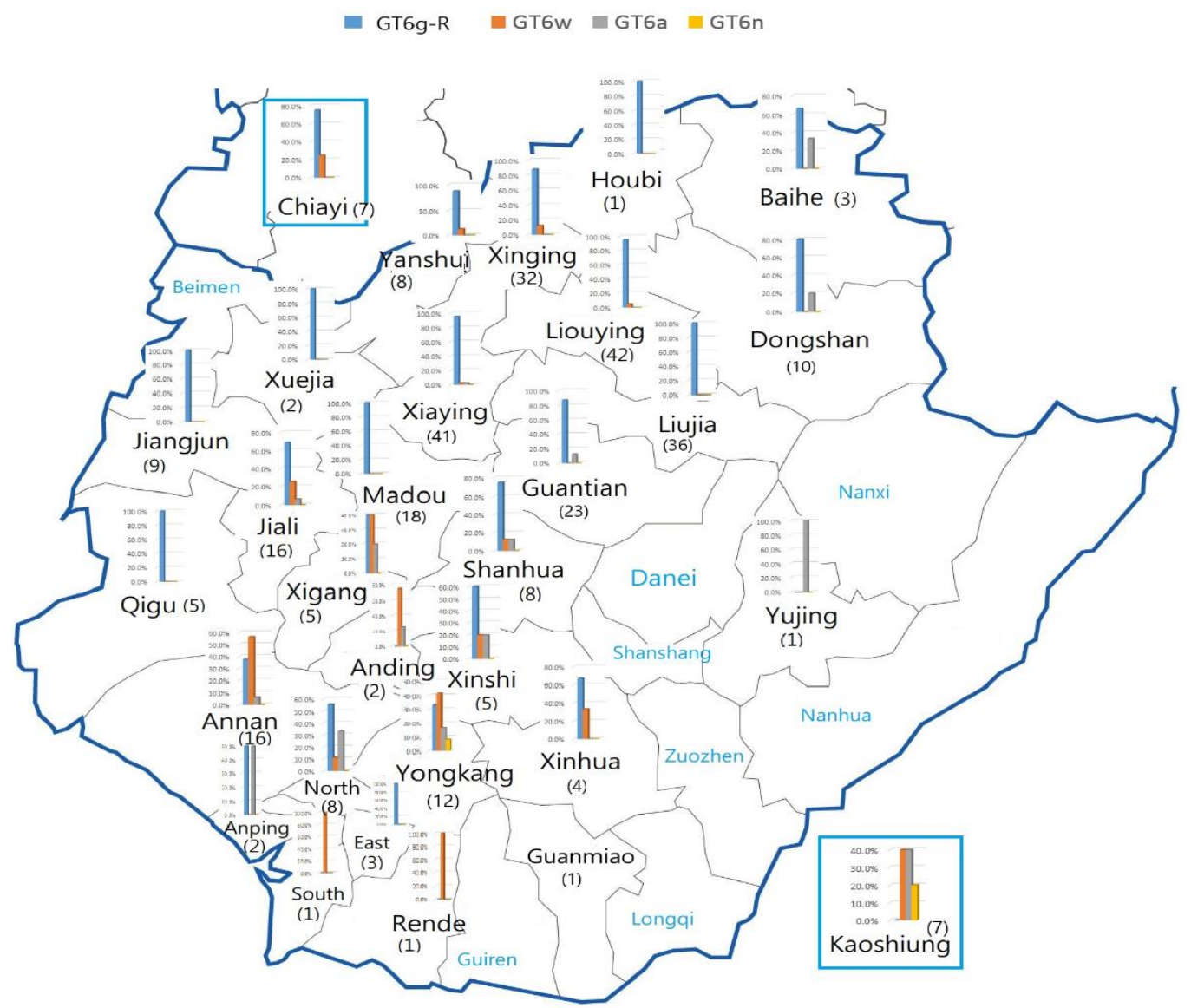

Figure 2. Percentages and numbers of major HCV GT 6 subtypes in Tainan.

\subsection{Diagnostic Procedures}

Study Design

The working flow of HCV genotype determination had been reported previously [18,19]. In brief, the Abbott Realtime Genotype II (Des Plaines, IL, USA) was used to determine HCV GTs successfully in 2568 patients, then Abbott Realtime Genotype II PLUS assay (Des Plaines, IL, USA) was used when Realtime GT II revealed ambiguous results (GT 1 without subtype, indeterminate, mixed, or undetected) in 567 patients. Nonstructural protein 5B (NS5B) and core/E1 sequencing were conducted to check genotypes when PLUS assays still could not determine the genotypes in 204 patients.

\subsection{Genotyping by Abbott GT II and PLUS Assays}

For analysis GTs with the Abbott GT II and PLUS assays, RNA was extracted from the $300 \mu \mathrm{L}$ serum on the Abbott $m 2000$ sp system using the Abbott $m$ Sample Preparation System kit (Des Plaines, IL, USA) according to the manufacturer's instruction. Reverse transcription (RT)-PCR master mixes were set up using the Abbott m2000sp and Abbott RealTime HCV Genotype II Amplification Reagent Kit or the RealTime HCV Genotype PLUS Amplification Reagent Kit (Des Plaines, IL, USA). RT-PCR reactions were performed using the Abbott m2000rt instrument.

\subsection{Genotyping by 5'UTR/Core Sequencing}

HCV RNA was extracted from $300 \mu \mathrm{L}$ patient's serum; nested PCRs were performed using Invitrogen kit to amplify the $5^{\prime} \mathrm{UTR}$ and core regions. For cDNA synthesis and the nested PCR, in the first PCR round, the outer primers corresponding to HCV-1 H77 sequence -268 to -251 (5'-AGCGTCTAGCCATTGGCGT- $\left.3^{\prime}\right)$ and antisense primer core $391-410$ (5'-ATGTACCCCATGAGGTCGGC-3') were used [20]. Nested PCR primers were -199 
to -183 (5'-GTGGTCTGCGGAACCGG-3') and antisense core 364-383 (5'-CAC/TGTA/ GAGGGTATCGATGAC-3') [21,22]. PCR products lengths were 681 and 589 bps, respectively, which were purified and sequenced for analysis. Sequences generated were aligned using Basic Local Alignment Search Tool (BLAST) of NCBI database to determine genotypes.

\subsection{Subtyping by E1 and NS5B Sequencing}

HCV RNA was extracted from $300 \mu \mathrm{L}$ of serum using LabTurbo viral Mini Kit (Taigen, Taipei, Taiwan) according to the recommended protocol. cDNA and PCR was synthesized from $10 \mu \mathrm{L}$ extracted RNA with Superscript ${ }^{\mathrm{TM}}$ One-Step RT-PCR system (Invitrogen, Life Technologies, Carlsbad, CA, USA) and outer primers specific for the E1 and NS5B. Sequencing of the E1 and NS5B regions was achieved by nested PCR using 1 2 $\mu \mathrm{L}$ PCR product, inner primers, and GoTaq ${ }^{\circledR}$ Master Mixes (Promega, Madison, WI, USA). The primers of the partial E1 region (reference strain H77 positions: 847-1325 nt) for nested PCR were described below: outer forward (E1) 5'-GGATYAAYTATGCAACAGGGAATCTWCCYGG-3', outer reverse (E2) 5'-GTCCKRTTTATRTGCCARCTGCCRTT-3'; inner forward (E3) 5'TTCGCCGACCTCATGGGGTACAT-3' ${ }^{\prime}$ inner reverse (E4) 5'-GGACCAGTTCATCATCATA TCCCA-3' ${ }^{\prime}$. The primers of the partial NS5B region (reference strain H77 positions: 8297$8690 \mathrm{nt}$ ) for nested PCR are described below: outer forward (N1) 5'-GTGGCGCTCMAAGA ARACYCCWATGGG-3' ${ }^{\prime}$, outer reverse (N2) 5'-CCAGGARTTSACTGGAGTGTGNCGRGCB GT-3'; inner forward (N3) $5^{\prime}$-TGGGNTTYTCTTAYGACACCAGRTGYTTTGA-3' ${ }^{\prime}$, inner reverse (N4) 5'-TACCTGGTCATAGCNTCCGTGAANGCTC-3'. One-Step RT-PCR using outer primers was conducted with the following conditions: $48^{\circ} \mathrm{C}$ for $40 \mathrm{~min}$ of cDNA synthesis and PCR stage by $95^{\circ} \mathrm{C}$ for $5 \mathrm{~min}, 35$ cycles of $95^{\circ} \mathrm{C}$ for $1 \mathrm{~min}, 55^{\circ} \mathrm{C}$ for $1 \mathrm{~min}$, and $72{ }^{\circ} \mathrm{C}$ for $2 \mathrm{~min}$, then a final cycle at $72{ }^{\circ} \mathrm{C}$ for $10 \mathrm{~min}$. Second round PCR using inner primers was conducted with the following conditions: $95^{\circ} \mathrm{C}$ for $5 \mathrm{~min}, 35$ cycles of $95^{\circ} \mathrm{C}$ for $30 \mathrm{~s}, 55^{\circ} \mathrm{C}$ for $30 \mathrm{~s}$, and $72{ }^{\circ} \mathrm{C}$ for $1 \mathrm{~min}$, then a final cycle at $72{ }^{\circ} \mathrm{C}$ for $10 \mathrm{~min}$. The amplicons were identified on $2.0 \%$ agarose gel. To avoid potential contamination, experimental procedures were strictly performed by adding negative controls and processed in parallel, including preparation of reagents, RT-PCR, nested PCR, and gel electrophoresis.

\subsection{Phylogenetic Analysis by E1 and NS5B Sequencing}

Sequencing was done with primers E3 and N3 using ABI Prism Big Dye 3.0 terminators on an ABI 3730xl DNA Analyzer (PE Applied Biosystems, Foster City, CA, USA). The nucleotide sequences obtained were aligned with HCV strains of standard genotypes and edited by the ClustalW method of MEGA software (Version X) [23]. The phylogenetic analysis was inferred using the neighbor-joining method. The percentages of replicate trees in which the associated taxa clustered together in the bootstrap test (1000 replicates) are shown next to the branches. The tree is drawn to scale, with branch lengths in the same units as those of the evolutionary distances used to infer the phylogenetic tree. The evolutionary distances were computed using the Kimura 2-parameter method and are in the units of the number of base substitutions per site. Codon positions included were $1 \mathrm{st}+2 \mathrm{nd}+3 \mathrm{rd}+$ Noncoding. All positions with less than $95 \%$ site coverage were eliminated, i.e., fewer than $5 \%$ alignment gaps, missing data, and ambiguous bases were allowed at any position (partial deletion option).

The study was approved by ethical committee of Chi Mei Medical Center, and informed consent was obtained from each patient. All experiments were performed in accordance with relevant guidelines and regulations. The study was conducted according to the guidelines of the Declaration of Helsinki.

The significance of possible associations between discrete variables was compared using chi-square test. The continuous variables were compared with student $t$ test. The level of statistical significance was set at two-tailed $p<0.05$. 


\section{Results}

The overall numbers and prevalence rates of HCV GT 1a, 1b, 2, 3, 4, 6, and mixed types among chronic hepatitis $\mathrm{C}(\mathrm{CHC})$ patients were 119 (3.9\%), $956(31.6 \%), 1388(45.9 \%)$ $19(0.6 \%), 7(0.2 \%), 518(17.1 \%)$, and $15(0.5 \%)$, respectively (Table 1$)$. There were no GT 5 and very rare GT 3 and 4 (combined less than 1\%). Genotypes 2 and $1 \mathrm{~b}$ remained two major prevalent HCV genotypes in Tainan, as supported by previous studies, but with higher GT 2 and much lower GT 1b prevalence [11-14]. HCV GT 6 prevalence rate $17.1 \%$ was significantly higher than previous studies reported but similar to our previous, smaller study (18.3\%) [18]. Numbers and percentages of each HCV GT of 36 districts are shown in Table 1 and Figure 1.

Table 1. Distribution of HCV genotypes of 36 districts of Tainan city.

\begin{tabular}{|c|c|c|c|c|c|c|c|c|c|}
\hline Region & Districts & GT1a & GT1b & GT2 & GT3 & GT4 & GT6 & MT & $T(n)$ \\
\hline \multirow[t]{7}{*}{1} & Baihe & 0 & 6 & 5 & 0 & 0 & 5 & 0 & 16 \\
\hline & Dongshan & 1 & 21 & 36 & 0 & 0 & 21 & 1 & 80 \\
\hline & Liouying & 4 & 53 & 75 & 0 & 0 & 65 & 1 & 198 \\
\hline & Liujia & 2 & 30 & 70 & 1 & 0 & 67 & 1 & 171 \\
\hline & Xiaying & 3 & 82 & 83 & 2 & 0 & 65 & 3 & 238 \\
\hline & Guantian & 5 & 31 & 48 & 1 & 1 & 41 & 1 & 128 \\
\hline & Danei & 1 & 5 & 7 & 1 & 0 & 2 & 0 & 16 \\
\hline \multirow[t]{6}{*}{2} & Xuejia & 2 & 27 & 20 & 0 & 0 & 3 & 0 & 52 \\
\hline & Madou & 12 & 25 & 66 & 0 & 1 & 23 & 1 & 128 \\
\hline & Jiangjun & 2 & 19 & 82 & 0 & 0 & 24 & 1 & 128 \\
\hline & Chiali & 6 & 45 & 63 & 0 & 1 & 22 & 0 & 137 \\
\hline & Xigang & 1 & 17 & 22 & 0 & 0 & 7 & 0 & 47 \\
\hline & Qigu & 0 & 26 & 38 & 0 & 0 & 7 & 0 & 71 \\
\hline \multirow[t]{19}{*}{3} & Nanxi & 0 & 5 & 6 & 0 & 0 & 1 & 0 & 12 \\
\hline & Yujing & 1 & 9 & 13 & 0 & 0 & 1 & 0 & 24 \\
\hline & Nanhua & 1 & 3 & 3 & 0 & 0 & 0 & 0 & 7 \\
\hline & Shanshang & 1 & 1 & 5 & 0 & 0 & 0 & 0 & 7 \\
\hline & Zuozhen & 0 & 0 & 2 & 0 & 0 & 0 & 0 & 2 \\
\hline & Shanhua & 6 & 12 & 20 & 0 & 0 & 11 & 0 & 49 \\
\hline & Xinshi & 2 & 16 & 23 & 1 & 0 & 5 & 1 & 48 \\
\hline & Xinhua & 0 & 28 & 49 & 0 & 1 & 9 & 1 & 88 \\
\hline & Guanmiao & 1 & 5 & 10 & 0 & 0 & 3 & 0 & 19 \\
\hline & Anding & 0 & 4 & 7 & 0 & 0 & 3 & 0 & 14 \\
\hline & Yongkang & 10 & 75 & 116 & 7 & 0 & 22 & 1 & 231 \\
\hline & Guiren & 3 & 11 & 24 & 0 & 0 & 2 & 0 & 40 \\
\hline & Annan & 8 & 42 & 69 & 1 & 1 & 20 & 0 & 141 \\
\hline & Anping & 2 & 27 & 51 & 0 & 1 & 3 & 0 & 84 \\
\hline & North & 6 & 35 & 36 & 1 & 0 & 16 & 0 & 94 \\
\hline & East & 2 & 23 & 33 & 2 & 0 & 8 & 0 & 68 \\
\hline & W. central & 1 & 16 & 21 & 0 & 0 & 4 & 0 & 42 \\
\hline & South & 3 & 13 & 35 & 1 & 1 & 2 & 0 & 55 \\
\hline & Rende & 3 & 8 & 9 & 0 & 0 & 2 & 1 & 23 \\
\hline \multirow[t]{5}{*}{4} & Houbi & 16 & 44 & 39 & 0 & 0 & 1 & 0 & 100 \\
\hline & Xinying & 12 & 146 & 132 & 1 & 0 & 43 & 1 & 335 \\
\hline & Yanshui & 2 & 44 & 57 & 0 & 0 & 10 & 1 & 114 \\
\hline & Beimen & 0 & 2 & 13 & 0 & 0 & 0 & 0 & 15 \\
\hline & Total & 119 & 956 & 1388 & 19 & 7 & 518 & 15 & 3022 \\
\hline
\end{tabular}

Two major rivers, Jishui River (JR) and Zengwen River (ZR), run through the Tainan city from eastern mountainous area to the western coast (blue lines in Figure 1). We divided into four regions according to geographic and $\mathrm{HCV}$ prevalence variations (thick black lines in Figure 1). From east to central, the upper stream area between JR and ZR was assigned as Region-1, including seven districts; the downstream area between JR and ZR was assigned 
as Region-2 with six districts; the southern area of ZR, almost half of Tainan city with 19 districts, we assigned as Region-3; and the northern area of JR was assigned as Region-4 with only four districts. Eleven of 13 districts with high HCV GT 6 prevalence > 15\% showed cluster between or adjacent to these two major rivers. All districts except one (Xuejia) located between JR and ZR (region 1 and 2) have prevalence of GT 6 more than 10\% (Figure 1).

Region-1 has the highest prevalence of HCV GT 6, 31.4\% (266/847); six of seven (85.7\%) districts showed prevalence of GT 6 more than 25\% (Figure 1), especially Liujia, with the highest (39.2\%) GT 6 prevalence; even the lowest-prevalence district (Danei) has $12.5 \%$. Genotype $1 \mathrm{a}, 1 \mathrm{~b}, 2$, 3, and 4 comprise $1.9,26.9,38.3,0.6$, and $0.1 \%$, respectively (Figure 1, Table 2).

Table 2. Geographic variation of prevalence of different HCV genotypes in Tainan.

\begin{tabular}{ccccccccccc}
\hline & \multicolumn{2}{c}{ Region-1 } & \multicolumn{2}{c}{ Region-2 } & \multicolumn{2}{c}{ Region-3 } & \multicolumn{2}{c}{ Region-4 } & \multicolumn{2}{c}{ Total } \\
\cline { 2 - 13 } & $\boldsymbol{n}$ & $\%$ & $\boldsymbol{n}$ & $\%$ & $\boldsymbol{n}$ & $\%$ & $\boldsymbol{n}$ & $\%$ & $\boldsymbol{n}$ & $\%$ \\
\hline GT 1a & 16 & $1.9 \%$ & 23 & $4.1 \%$ & 50 & $4.8 \%$ & 30 & $5.3 \%$ & 119 & $3.9 \%$ \\
GT 1b & 228 & $26.9 \%$ & 159 & $28.2 \%$ & 333 & $31.8 \%$ & 236 & $41.8 \%$ & 956 & $31.6 \%$ \\
GT 2 & 324 & $38.3 \%$ & 291 & $51.7 \%$ & 532 & $50.8 \%$ & 241 & $42.7 \%$ & 1388 & $45.9 \%$ \\
GT 3 & 5 & $0.6 \%$ & 0 & & 13 & $1.2 \%$ & 1 & $0.2 \%$ & 19 & $0.6 \%$ \\
GT 4 & 1 & $0.1 \%$ & 2 & $0.4 \%$ & 4 & $0.4 \%$ & 0 & & 7 & $0.2 \%$ \\
GT 6 & 266 & $31.4 \%$ & 86 & $15.3 \%$ & 112 & $10.7 \%$ & 54 & $9.6 \%$ & 518 & $17.1 \%$ \\
Mixed GT & 7 & $0.8 \%$ & 2 & $0.4 \%$ & 4 & $0.4 \%$ & 2 & $0.4 \%$ & 15 & $0.5 \%$ \\
\hline Total & 847 & $28.0 \%$ & 563 & $18.6 \%$ & 1048 & $34.7 \%$ & 564 & $18.7 \%$ & 3022 & \\
\hline
\end{tabular}

Region-2 has the highest GT 2 prevalence (51.7\%). The prevalence rates of GT $1 \mathrm{a}, 1 \mathrm{~b}, 2$, 4 , and 6 were $4.1,28.2,51.7,0.4$, and $15.3 \%$, respectively. In fact, one coastal village (Masago of Jiangjun District) was reported to have the highest HCV GT 2 prevalence $(63.5 \%)$ so far ever reported in Taiwan [24]. All these districts except one (Xeujia 5.8\%) have prevalence of GT $6>10 \%$.

Region-3 consists of 19 districts of southern Tainan. The prevalence rates of HCV GT $1 \mathrm{a}, 1 \mathrm{~b}, 2,3,4$, and 6 are $4.8,31.8,50.8,1.2,0.4$, and $10.7 \%$, respectively (Table 2 ). Two districts with higher GT 6 prevalence of $22.4 \%$ and $21.4 \%$, Shanhua and Anding, are located close to southern border of ZR. The prevalence rates of the rest districts are all under $15 \%$ except for two districts (North and Guanmiao districts, 16.8 and 15.8\%, respectively).

Region-4 consists of Houbi, Xinying, Yanshui, and Beimen, the four districts of northern Tainan. The prevalence rates of HCV GT 1a, 1b, 2, 3, and 6 are 5.3, 41.8, 42.7, 0.2, and $9.6 \%$, respectively. Xinying, with the highest GT 6 prevalence of $12.8 \%$, is located close to one high-GT 6 district in Region-1, Liouying (32.5\%).

The HCV GTs distribution of Region-1 showed significantly higher prevalence of GT 6 (Region-1 vs. Region-2, 3, 4; $p<0.00001$ ) and lower prevalence of GT 1b (Region-1 vs. Region-3, $4 ; p<0.05$ ) and GT 2 (Region-1 vs. Region-2, 3; $p<0.00001$ ).

The subtyping results were successfully obtained in 322 of 331 (97.3\%) of core/E1 and 320 of $331(96.7 \%)$ of NS5B sequences of CHC patients with GT 6 (including seven patients from Chiayi and seven patients from Kaohsiung, at the north and south of Tainan city, respectively) with available sera for PCR and sequencing. Subtyping results were concordant in 307 of 331 (92.7\%) of samples. The circular phylogenetic tree generated using E1 sequences with prototypes of GT 1 5, 7, and 8 and GT 6 subtypes confirmed these samples classified as GT 6 (Supplement Figure S1). However, most of our samples were not subtype 6g, as previously assumed (Supplemental Figure S2) [18,19]. Instead, these samples clustered with a novel subtype (closely related to $6 \mathrm{~g}$ ) reported by Hedskog et al. [25]. This patient was enrolled for Sofosbuvir-based therapy from the Liouying campus, and her HCV was typed as GT 1b [25]. It is known that "confirmation of a new subtype requires a complete or nearly complete coding region sequence differing from other sequences by at least $15 \%$ of nucleotide positions and sequence information from at 
least two other isolates in core/E1 (>90\% of the sequence corresponding to positions 869 to 1292 of the H77 reference sequence accession number AF009606) and NS5B ( $>90 \%$ of positions 8,276 to 8,615$)^{\prime \prime}$ [7], and the sequences of our samples covered $90.6 \%$ of core/E1 (909 to 1309) and $88.8 \%$ of NS5B (8316 to 8624) that are required for confirmation of new subtypes. Hence, we can almost ascertain that a new subtype closely related to $6 \mathrm{~g}$ is identified and confirmed (6xj). Even in the most distantly related sample (10784309), the homology of core/E1 and NS5B sequences between our samples and this novel subtype are still greater than $85 \%$ ( 85.2 and $92.2 \%$, respectively, data not shown). Meanwhile, there are three samples (10514010; 21004325; and 10134166) clustered together that could be another potential novel subtype (closely related to $6 \mathrm{w}$ ) once a complete coding region sequence is available (Supplement Figure S3A,B).

Subtypes of HCV GT 6 that we determined in this area included 6a, g-related, n, t, v, and $\mathrm{w}$, but only four subtypes - $6 \mathrm{a}$, g-related, $\mathrm{n}$, and $\mathrm{w}$ - showed concordant typing results between core/E1 and NS5B regions. This novel 6g-related subtype is the most prevalent subtype in $79.8 \%(245 / 307)$ of HCV GT 6 samples $(81.0 \%, 239 / 295$ of Tainan samples), followed by $6 \mathrm{w} 11.4 \%$ (35), 6a 7.5\% (24), and 6n 1.0\% (3) (Table 3, Figure 2).

Table 3. Distribution of subtypes of 331 HCV GT 6 patients of 29 districts of Tainan city, Chiayi, and Kaohsiung.

\begin{tabular}{|c|c|c|c|c|c|c|c|c|c|c|c|c|}
\hline Region & Districts & GT6a & $\%$ & GT6g & $\%$ & GT6n & $\%$ & GT6w & $\%$ & ID & $\%$ & Total \\
\hline \multirow[t]{7}{*}{1} & Baihe & 1 & $33.3 \%$ & 2 & $66.7 \%$ & 0 & $0.0 \%$ & 0 & $0.0 \%$ & 0 & $0.0 \%$ & 3 \\
\hline & Dongshan & 1 & $10.0 \%$ & 4 & $40.0 \%$ & 0 & $0.0 \%$ & 0 & $0.0 \%$ & 5 & $50.0 \%$ & 10 \\
\hline & Liouying & 0 & $0.0 \%$ & 38 & $90.5 \%$ & 0 & $0.0 \%$ & 2 & $4.8 \%$ & 2 & $4.8 \%$ & 42 \\
\hline & Liujia & 0 & $0.0 \%$ & 34 & $94.4 \%$ & 0 & $0.0 \%$ & 0 & $0.0 \%$ & 2 & $5.6 \%$ & 36 \\
\hline & Xiaying & 1 & $2.4 \%$ & 39 & $95.1 \%$ & 0 & $0.0 \%$ & 1 & $2.4 \%$ & 0 & $0.0 \%$ & 41 \\
\hline & Guantian & 3 & $13.0 \%$ & 19 & $82.6 \%$ & 0 & $0.0 \%$ & 0 & $0.0 \%$ & 1 & $4.3 \%$ & 23 \\
\hline & & 6 & $3.9 \%$ & 136 & $87.7 \%$ & 0 & $0.0 \%$ & 3 & $1.9 \%$ & 10 & $6.5 \%$ & 155 \\
\hline \multirow[t]{7}{*}{2} & Xuejia & 0 & $0.0 \%$ & 2 & $100.0 \%$ & 0 & $0.0 \%$ & 0 & $0.0 \%$ & 0 & $0.0 \%$ & 2 \\
\hline & Madou & 0 & $0.0 \%$ & 18 & $100.0 \%$ & 0 & $0.0 \%$ & 0 & $0.0 \%$ & 0 & $0.0 \%$ & 18 \\
\hline & Jiangjun & 0 & $0.0 \%$ & 9 & $100.0 \%$ & 0 & $0.0 \%$ & 0 & $0.0 \%$ & 0 & $0.0 \%$ & 9 \\
\hline & Jiali & 0 & $0.0 \%$ & 11 & $68.8 \%$ & 1 & $6.3 \%$ & 4 & $25.0 \%$ & 0 & $0.0 \%$ & 16 \\
\hline & Xigang & 1 & $20.0 \%$ & 2 & $40.0 \%$ & 0 & $0.0 \%$ & 2 & $40.0 \%$ & 0 & $0.0 \%$ & 5 \\
\hline & Qigu & 0 & $0.0 \%$ & 4 & $80.0 \%$ & 0 & $0.0 \%$ & 0 & $0.0 \%$ & 1 & $20.0 \%$ & 5 \\
\hline & & 1 & $1.8 \%$ & 46 & $83.6 \%$ & 1 & $1.8 \%$ & 6 & $10.9 \%$ & 1 & $1.8 \%$ & 55 \\
\hline \multirow[t]{15}{*}{3} & Yujing & 1 & $100.0 \%$ & 0 & $0.0 \%$ & 0 & $0.0 \%$ & 0 & $0.0 \%$ & 0 & $0.0 \%$ & 1 \\
\hline & Shanhua & 1 & $12.5 \%$ & 6 & $75.0 \%$ & 0 & $0.0 \%$ & 1 & $12.5 \%$ & 0 & $0.0 \%$ & 8 \\
\hline & Xinhua & 0 & $0.0 \%$ & 2 & $50.0 \%$ & 0 & $0.0 \%$ & 1 & $25.0 \%$ & 1 & $25.0 \%$ & 4 \\
\hline & Xinshi & 1 & $20.0 \%$ & 3 & $60.0 \%$ & 0 & $0.0 \%$ & 1 & $20.0 \%$ & 0 & $0.0 \%$ & 5 \\
\hline & Guanmiao & 1 & $100.0 \%$ & 0 & $0.0 \%$ & 0 & $0.0 \%$ & 0 & $0.0 \%$ & 0 & $0.0 \%$ & 1 \\
\hline & Yongkang & 2 & $16.7 \%$ & 3 & $25.0 \%$ & 1 & $8.3 \%$ & 4 & $33.3 \%$ & 2 & $16.7 \%$ & 12 \\
\hline & Anding & 1 & $50.0 \%$ & 0 & $0.0 \%$ & 0 & $0.0 \%$ & 1 & $50.0 \%$ & 0 & $0.0 \%$ & 2 \\
\hline & Annan & 1 & $6.3 \%$ & 5 & $31.3 \%$ & 0 & $0.0 \%$ & 9 & $56.3 \%$ & 1 & $6.3 \%$ & 16 \\
\hline & Anping & 1 & $50.0 \%$ & 1 & $50.0 \%$ & 0 & $0.0 \%$ & 0 & $0.0 \%$ & 0 & $0.0 \%$ & 2 \\
\hline & North & 2 & $25.0 \%$ & 5 & $62.5 \%$ & 0 & $0.0 \%$ & 1 & $12.5 \%$ & 0 & $0.0 \%$ & 8 \\
\hline & East & 0 & $0.0 \%$ & 3 & $100.0 \%$ & 0 & $0.0 \%$ & 0 & $0.0 \%$ & 0 & $0.0 \%$ & 3 \\
\hline & W. central & 0 & $0.0 \%$ & 0 & $0.0 \%$ & 0 & $0.0 \%$ & 0 & $0.0 \%$ & 2 & $100.0 \%$ & 2 \\
\hline & South & 0 & $0.0 \%$ & 0 & $0.0 \%$ & 0 & $0.0 \%$ & 1 & $100.0 \%$ & 0 & $0.0 \%$ & 1 \\
\hline & Rende & 0 & $0.0 \%$ & 0 & $0.0 \%$ & 0 & $0.0 \%$ & 1 & $100.0 \%$ & 0 & $0.0 \%$ & 1 \\
\hline & & 11 & $16.7 \%$ & 28 & $42.4 \%$ & 1 & $1.5 \%$ & 20 & $30.3 \%$ & 6 & $9.1 \%$ & 66 \\
\hline \multirow[t]{6}{*}{4} & Houbi & 0 & $0.0 \%$ & 1 & $100.0 \%$ & 0 & $0.0 \%$ & 0 & $0.0 \%$ & 0 & $0.0 \%$ & 1 \\
\hline & Xinying & 4 & $12.5 \%$ & 22 & $68.8 \%$ & 0 & $0.0 \%$ & 2 & $6.3 \%$ & 4 & $12.5 \%$ & 32 \\
\hline & Yanshui & 0 & $0.0 \%$ & 6 & $75.0 \%$ & 0 & $0.0 \%$ & 1 & $12.5 \%$ & 1 & $12.5 \%$ & 8 \\
\hline & & 4 & $9.8 \%$ & 29 & $70.7 \%$ & 0 & $0.0 \%$ & 3 & $7.3 \%$ & 5 & $12.2 \%$ & 41 \\
\hline & Chiayi & 0 & $0.0 \%$ & 6 & $85.7 \%$ & 0 & $0.0 \%$ & 1 & $14.3 \%$ & 0 & $0.0 \%$ & 7 \\
\hline & Kaohsiung & 2 & $28.6 \%$ & 0 & $0.0 \%$ & 1 & $14.3 \%$ & 2 & $28.6 \%$ & 2 & $28.6 \%$ & 7 \\
\hline
\end{tabular}


The geographic distribution and ratios of 307 HCV GT 6 subtypes from 29 districts of Tainan, Chiayi, and Kaohsiung are summarized in Table 3 and Figure 2. The distribution of $6 \mathrm{w}$ is clearly located in southwestern Tainan, mainly south of ZR, while the novel $6 \mathrm{~g}$ related subtype is distributed at north of Tainan, especially in Region-1, and Chiayi but not Kaohsiung. Subtype 6a was found in downtown area and mountainous area of upstream of ZR. HCV GT 6 infection is relatively rare in hilly southeastern Tainan.

The age distribution of HCV GT 6 subtypes is depicted in Figure 3. Subtypes 6grelated and $6 \mathrm{w}$ were significantly older than $6 \mathrm{a}$ and $6 \mathrm{n}$, suggesting different time and routes of transmission existed in these patients.

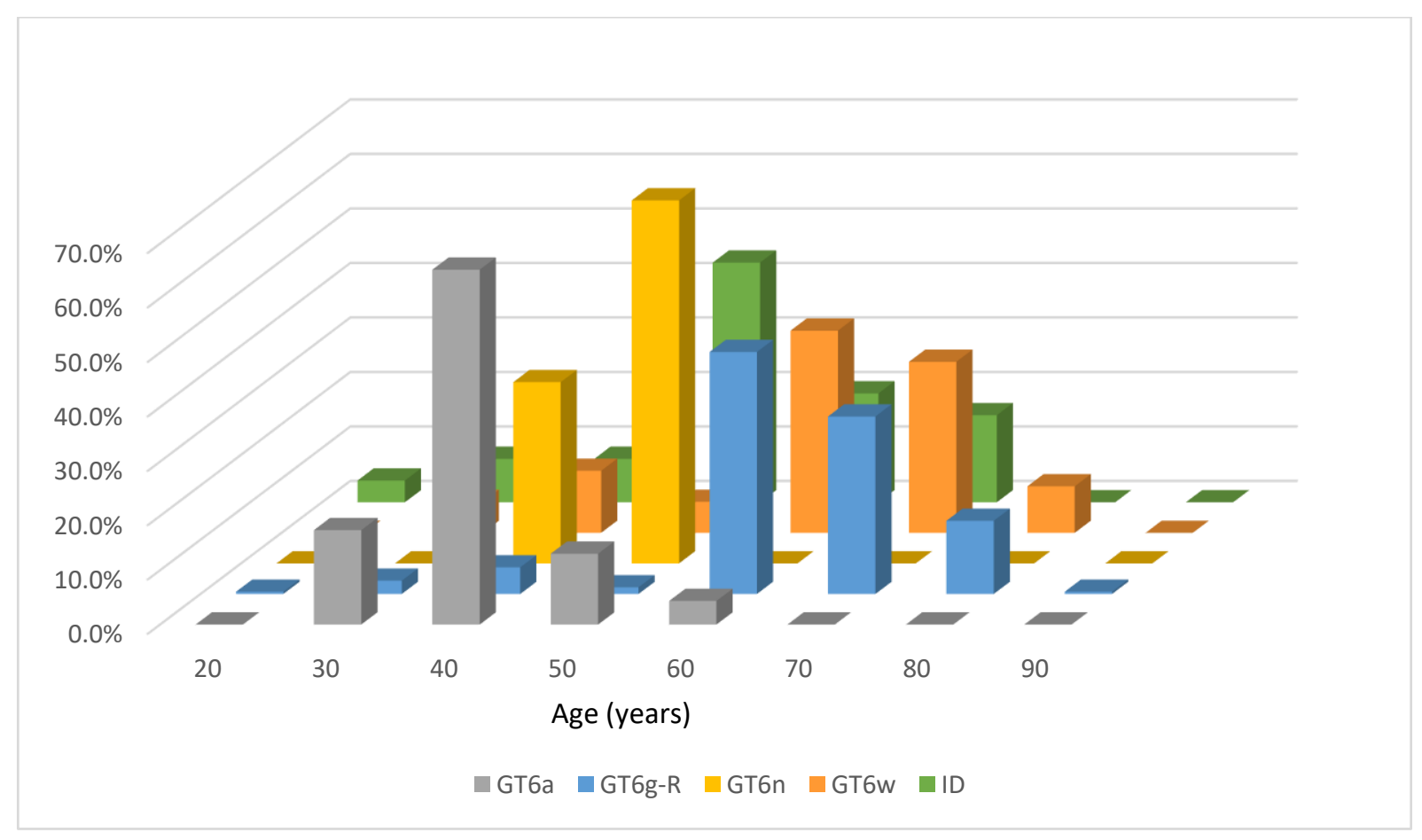

Figure 3. Percentages of age distribution of HCV GT 6 subtypes. ID, indeterminate.

\section{Discussions}

In this study, more than five hundred HCV viremic patients carried GT 6 in Tainan, southern Taiwan. This is the largest number of HCV GT 6 infections ever reported in Taiwan. In contrast to the peninsular Southeast Asia, with endemic HCV GT 6 infection, GT 6 infection is rarely reported in community or hospital-based studies from Taiwan. In an earlier study from southern Taiwan, only 2 of $418(0.5 \%) \mathrm{HCV}$ patients were infected with GT 6a [13]. One of the reasons of such low HCV GT 6 prevalence in earlier studies could be the limitation of earlier genotyping assays. Earlier studies using line-probe assay or PCR with type-specific primers aimed for $5^{\prime}$ untranslated region $\left(5^{\prime} \mathrm{UTR}\right)$ for genotypes determination could not detect GT 6 [11,12,26,27]. High genetic conservation of $5^{\prime}$ UTR is suitable for PCR amplification and RNA detection but lacks sufficient variation to distinguish some GT 1 and 6 and some subtypes [28-30]. We have found a high rate of HCV GT 1 without subtype designation using Abbott Realtime HCV GT II assay for $\mathrm{HCV}$ genotyping in our medical system since 2016. Among these GT 1 without subtype designation, nearly $80 \%$ were confirmed to be GT 6 by Abbott Realtime HCV GT II PLUS and core/E1 sequencing [18]. Besides subtypes 6a and 6b, Abbott Realtime HCV GT II PLUS assay detects more GT 6 subtypes (6c-6l) and subtypes 1a and $1 \mathrm{~b}$ in a single reaction [31]. In our previous study, 163 of 210 samples with ambiguous result by Abbott Realtime HCV GT II were identified as GT 6 by GT II PLUS [18]. Hence, it is reasonable 
to assume that such a higher GT 6 detection rate was due to increased detection of novel 6g-related subtype in this study.

Another reason of low HCV GT 6 prevalence in earlier reports from Taiwan might be that the distribution of HCV GT 6 is highly geographic restricted in Tainan, as this novel subtype was mainly restricted between two main rivers, and $6 \mathrm{w}$ was restricted in southern Tainan, suggesting a local endemic disease with considerable duration. Also, 6g-related subtype was found in Chiayi (north of Tainan) but not Kaohsiung (south of Tainan), albeit the case numbers are small.

Four HCV GT 6 subtypes, including 6g-related, w, a, and n, were identified in this study, but only this novel 6g-related subtype was first reported in Taiwan (misjudged as $6 \mathrm{~g}$ simply from BLAST results) $[18,19]$. HCV GT 6,3 , and 1a were highly prevalent among IDUs, with HIV and subtype 6a having been reported as the main GT 6 subtype (23.5 37.9\%) [16,17,32], followed with $6 \mathrm{~g}, \mathrm{k}, \mathrm{n}$, and w. extremely high anti-HCV prevalence rates from 96.6 98.7\% among IDUs with HIV had been reported in Taiwan $[17,32,33]$. This is mostly because an outbreak of HIV with recombinant circulating form (CRF) 07_BC was spread among IDUs in Taiwan since 2003 and peaked in $2005[34,35]$ along with even greater HCV outbreak since both viruses share similar transmission routes and even higher transmission efficiency [16]. A molecular epidemiological study showed these CRF07_BC HIV sequences from Taiwan resemble the dominant strains circulating among IDUs in China [35]. Evolutionary analyses also revealed that CRF07_BC was introduced into southern Taiwan in 1998-2001 and spread to central-northern Taiwan in 2001-2003 [36], causing the largest HIV/AIDS and also HCV outbreaks in Taiwan $[16,17,32,34,35,37]$. The origins of CRF07_BC HIV and HCV could be traced to Yunnan Province, China, and transmitted via heroin-trafficking routes $[17,38]$. Interestingly, $6 \mathrm{~g}$ and $6 \mathrm{w}$ had not been reported in Yunnan and peninsular Southeast Asia but from Hong Kong, Guangzhou, China, and Indonesia [39-41]. In a large study of HCV genotypes and subtypes circulating in China, 4 GTs and 18 subtypes were identified among 32,030 patients; hepatitis $C$ virus GT 6 infections were detected in 2332 samples $(7.28 \%)$, with the most prevalent being 6a (2045/2332), followed by 6n (226), 6u (36), 6g (4), 6v (2), 6w (2), and 6e, b, j, q, and r (each 1) [42]. Given the large number of old-aged, 6g-related and $6 \mathrm{w}$ and less than $10 \%$ younger $6 \mathrm{a} / 6 \mathrm{n}$ patients in our study, it seemed less likely that $6 \mathrm{~g}$-related and $6 \mathrm{w}$ were transmitted from China to Taiwan or disseminated from IDUs after 2003 outbreak. Subtype 6a and 6n were transmitted from China and Southeast Asia via heroin-trafficking routes, as these patients who carried subtype $6 \mathrm{a}$ and $6 \mathrm{n}$ were significantly younger and with higher ratio of self-reported IDU history (also GT 1a, data not shown). From the phylogenetic trees of E1 and NS5B, 6w D140, and D370 prototypic stains clustered closely with our samples (Supplement Figure S3A,B), further supporting that $6 \mathrm{w}$ detected among IDUs could be spilled over from this area, as only two $6 \mathrm{w}$ and one $2 \mathrm{~b} 6 \mathrm{w}$ recombinant had been reported among hundreds IDUs/HIV in Taiwan [16,17,32]. The ages, transmission history and epidemiology of these patients with novel 6g-related subtype and $6 \mathrm{w}$ were obviously different from GT $6 \mathrm{a} / \mathrm{n}$ patients.

Studies from Hainan island of China, which is close to Vietnam, reported a unique ecosystem of Li tribe (controversially as Austronesian descendants) with HCV infection maintained over 600 years with many novel GT 6 strains sharing a common ancestor with subtype $6 \mathrm{~g}$ and $6 \mathrm{w}$ dating from the end of the 12th century [43-45]. From the evolutional and time-scaled phylogenetical analyses, $\mathrm{HCV}$ subtypes $6 \mathrm{~g}$ and $6 \mathrm{w}$ have co-evolved and diverted from group of GT 6 subtypes $c \sim f, o \sim u, x c$, xf, and $x h$ for centuries $[6,7,9,46,47]$. Similarly, there are three samples clustered but not belonging to $6 \mathrm{~W}$ or $6 \mathrm{~g}$-related subtypes that comprise a potential novel subtype. These three samples shared a common ancestor with $6 \mathrm{~g}, \mathrm{w}$, and $6 \mathrm{~g}$-related subtypes, suggesting a long-term HCV infection history existed in Tainan as Hainan island studies shown. Interestingly, the divergence of HCV in Tainan was less prominent than Hainan island. About $80 \%$ of GT 6 infections were due to this novel 6g-related subtype. Such a closely related novel $6 \mathrm{~g}$-related subtype distribution could be due to the founder effect of the small population of indigenous people who resided in 
the ancient Taiwan island. Before Hans people immigrated to Taiwan in the 17th century, the population size of indigenous people might have been able to sustain low levels of $\mathrm{HCV}$ transmission and infection. Hence, only a few HCV strains were maintained and circulated in this area until more efficient transmission routes were introduced and caused endemic spread in the 20th century. This scenario was similar to the GT 6 history observed in Southeast Asia [6]. The surging of HCV-related HCC in southwest Taiwan after 1980 also supports this observation [48].

In contrast to the Hainan $\mathrm{Li}$ tribe population that resided in a relatively closed environment, Taiwan has been populated by Austronesian populations for six-thousand years, occupied by Ming-Qing dynasties for hundreds of years, and colonized by Spain, Netherland, and Japan for decades, also with massive populations migrating from China to Taiwan after World War II. The epidemiological history of HCV among the indigenous Austronesian tribe (Siraya tribe, plains indigenous people) who resided in Tainan for centuries seemed more difficult to recover.

In conclusion, from the geographic restriction, chronological events, and evolutional and phylogenetic evidences, we identified that novel 6g-related and 6w HCV subtypes could be indigenous in Tainan, southern Taiwan. The infection history might last several hundred years from the phylogenetic evidence with new subtypes evolution. Subtype $6 \mathrm{w}$ among IDUS could be spilled over from this area. This should be able to prevent stigmatization of these older HCV GT 6 patients as IDU related and also shed some light on the understanding of HCV GT 6 history in Southeast Asia. New emerging strains such as $6 \mathrm{a}, \mathrm{k}$, and $\mathrm{n}$ as well as $1 \mathrm{a}$ and 3 were most likely spread along HIV CRF07_BC outbreak after the 21st century. Existence of potentially new subtypes could be anticipated, and the phylogenetic relatedness with Hainan strains is awaiting for further complete genome data to answer.

Supplementary Materials: The following are available online at https:/ /www.mdpi.com/article/10 .3390/v13071316/s1, Figure S1: Circular neighbor-joining phylogenetic tree of E1 sequences of GT 6 samples with confirmed GT 6 subtypes and GT 1-5, 7 and 8; Figure S2: Radiation neighbor-joining tree of E1 sequences of GT 6 samples with confirmed GT 6 subtypes and GT 1-5, 7 and 8; Figure S3: Neighbor-joining trees of ten 6 g-related, ten $6 \mathrm{w}$, three $6 \mathrm{n}$ and 3 potential new subtype sequences with confirmed GT 6 subtypes and 6g-related novel subtypes from Hainan island, A: E1, B: NS5B.

Author Contributions: Conceptualization, J.-J.C.; Data curation, H.-D.T., P.-L.L., H.-T.K., M.-J.S., C.-T.C., T.-W.C., H.-J.K., Y.-H.W., M.-G.P., C.-H.L. and C.L.; Formal analysis, J.-J.C.; Funding acquisition, H.-D.T.; Methodology, C.-Y.H., H.-H.T. and L.-C.W.; Project administration, P.-L.L. and J.-J.C.; Resources, P.-L.L.; Software, C.-Y.H., H.-H.T. and L.-C.W.; Writing—original draft, H.-D.T. and J.-J.C.; Writing - review \& editing, H.-D.T. All authors have read and agreed to the published version of the manuscript.

Funding: This research received no external funding.

Institutional Review Board Statement: The study was approved by ethical committee of Chi Mei Medical Center. IRB approval number: 10705-L03.

Informed Consent Statement: Informed consent was obtained from each patient. All experiments were performed in accordance with relevant guidelines and regulations. The study was conducted according to the guidelines of the Declaration of Helsinki.

Data Availability Statement: The data that support the findings of this study are available from the corresponding author upon reasonable request.

Acknowledgments: The authors wish to acknowledge the help of Wen-Ya Ko of National Yang-Ming University in phylogenetic analysis.

Conflicts of Interest: The authors declare no conflict of interest. 


\section{References}

1. Childs, K.; Davis, C.; Cannon, M.; Montague, S.; Filipe, A.; Tong, L.; Simmonds, P.; Smith, D.; Thomson, E.C.; Dusheiko, G.; et al. Suboptimal SVR rates in African patients with atypical genotype 1 subtypes: Implications for global elimination of hepatitis C. J. Hepatol. 2019, 71, 1099-1105. [CrossRef] [PubMed]

2. Nguyen, D.T.; Tran, T.T.T.; Nghiem, N.M.; Le, P.T.; Vo, Q.M.; Day, J.; Rahman, M.; Le, H.M. Effectiveness of sofosbuvir based direct-acting antiviral regimens for chronic hepatitis C virus genotype 6 patients: Real-world experience in Vietnam. PLoS ONE 2020, 15, e0233446. [CrossRef]

3. Chen, J.J.; Lee, P.L.; Chiu, H.C.; Tung, H.D.; Chiu, Y.C.; Cheng, P.N. Real-world effectiveness and safety of ledipasvir/sofosbuvir for genotype 6 chronic hepatitis C patients in Taiwan. J. Gastroenterol. Hepatol. 2020, 35, 467-472. [CrossRef]

4. Mettikanont, P.; Bunchorntavakul, C.; Reddy, K.R. Systematic review: Epidemiology and response to direct-acting antiviral therapy in genotype 6 chronic hepatitis C virus infection. Aliment. Pharmacol. Ther. 2019, 49, 492-505. [CrossRef] [PubMed]

5. Smith, D.B.; Davidson, F.; Simmonds, P. Hepatitis C virus variants and the role of genotyping. J. Hepatol. 1995, 23 (Suppl. 2), 26-31.

6. Pybus, O.G.; Barnes, E.; Taggart, R.; Lemey, P.; Markov, P.V.; Rasachak, B.; Syhavong, B.; Phetsouvanah, R.; Sheridan, I.; Humphreys, I.S.; et al. Genetic history of hepatitis C virus in East Asia. J. Virol. 2009, 83, 1071-1082. [CrossRef] [PubMed]

7. Smith, D.B.; Bukh, J.; Kuiken, C.; Muerhoff, A.S.; Rice, C.M.; Stapleton, J.T.; Simmonds, P. Expanded classification of hepatitis C virus into 7 genotypes and 67 subtypes: Updated criteria and genotype assignment web resource. Hepatology 2014, 59, 318-327. [CrossRef] [PubMed]

8. Wasitthankasem, R.; Vongpunsawad, S.; Siripon, N.; Suya, C.; Chulothok, P.; Chaiear, K.; Rujirojindakul, P.; Kanjana, S.; Theamboonlers, A.; Tangkijvanich, P.; et al. Genotypic distribution of hepatitis C virus in Thailand and Southeast Asia. PLoS ONE 2015, 10, e0126764. [CrossRef] [PubMed]

9. Thong, V.D.; Akkarathamrongsin, S.; Poovorawan, K.; Tangkijvanich, P.; Poovorawan, Y. Hepatitis C virus genotype 6: Virology, epidemiology, genetic variation and clinical implication. World J. Gastroenterol. 2014, 20, 2927-2940. [CrossRef] [PubMed]

10. International Committee on Taxonomy of Viruses(ICTV). HCV Classification. Available online: https://talk.ictvonline.org/ictv_ wikis/flaviviridae/w/sg_flavi/56/hcv-classification (accessed on 23 April 2021).

11. Chen, C.H.; Sheu, J.C.; Wang, J.T.; Huang, G.T.; Yang, P.M.; Lee, H.S.; Lee, C.Z.; Chen, D.S. Genotypes of hepatitis C virus in chronic liver disease in Taiwan. J. Med. Virol. 1994, 44, 234-236. [CrossRef]

12. Kao, J.H.; Chen, P.J.; Lai, M.Y.; Yang, P.M.; Sheu, J.C.; Wang, T.H.; Chen, D.S. Genotypes of hepatitis C virus in Taiwan and the progression of liver disease. J. Clin. Gastroenterol. 1995, 21, 233-237. [CrossRef] [PubMed]

13. Lee, C.M.; Lu, S.N.; Hung, C.H.; Tung, W.C.; Wang, J.H.; Tung, H.D.; Chen, C.H.; Hu, T.H.; Changchien, C.S.; Chen, W.J. Hepatitis C virus genotypes in southern Taiwan: Prevalence and clinical implications. Trans. R. Soc. Trop. Med. Hyg. 2006, 100, 767-774. [CrossRef]

14. Chen, C.H.; Yang, P.M.; Huang, G.T.; Lee, H.S.; Sung, J.L.; Sheu, J.C. Estimation of seroprevalence of hepatitis B virus and hepatitis $\mathrm{C}$ virus in Taiwan from a large-scale survey of free hepatitis screening participants. J. Formos. Med. Assoc. 2007, 106, 148-155. [CrossRef]

15. Omata, M.; Kanda, T.; Yokosuka, O.; Crawford, D.; Al-Mahtab, M.; Wei, L.; Ibrahim, A.; Lau, G.K.; Sharma, B.C.; Hamid, S.S.; et al. Features of hepatitis $\mathrm{C}$ virus infection, current therapies and ongoing clinical trials in ten Asian Pacific countries. Hepatol. Int. 2015, 9, 486-507. [CrossRef] [PubMed]

16. Lee, Y.M.; Lin, H.J.; Chen, Y.J.; Lee, C.M.; Wang, S.F.; Chang, K.Y.; Chen, T.L.; Liu, H.F.; Chen, Y.M. Molecular epidemiology of HCV genotypes among injection drug users in Taiwan: Full-length sequences of two new subtype 6w strains and a recombinant form_2b6w. J. Med. Virol. 2010, 82, 57-68. [CrossRef]

17. Liu, J.Y.; Lin, H.H.; Liu, Y.C.; Lee, S.S.; Chen, Y.L.; Hung, C.C.; Ko, W.C.; Huang, C.K.; Lai, C.H.; Chen, Y.S.; et al. Extremely high prevalence and genetic diversity of hepatitis $\mathrm{C}$ virus infection among HIV-infected injection drug users in Taiwan. Clin. Infect. Dis. 2008, 46, 1761-1768. [CrossRef]

18. Chen, J.J.; Tung, H.D.; Lee, P.L.; Kuo, H.T.; Sheu, M.J.; Cheng, C.T.; Chuang, T.W.; Kao, H.J.; Lu, N.M.; Wu, L.C.; et al. High prevalence of genotype 6 hepatitis $\mathrm{C}$ virus infection in Southern Taiwan using Abbott genotype assays. J. Formos. Med. Assoc. 2020, 119, 413-419. [CrossRef]

19. Tung, H.D.; Lee, P.L.; Chen, J.J.; Kuo, H.T.; Sheu, M.J.; Cheng, C.T.; Chuang, T.W.; Kao, H.J.; Hou, C.Y.; Tsai, H.H.; et al. Geographic variation of genotype 6 hepatitis C virus infection in an endemic area of southern Taiwan. J. Formos. Med. Assoc. 2020, 119, 1876-1880. [CrossRef]

20. Bukh, J.; Purcell, R.H.; Miller, R.H. Sequence analysis of the 5' noncoding region of hepatitis C virus. Proc. Natl. Acad. Sci. USA 1992, 89, 4942-4946. [CrossRef]

21. Pohjanpelto, P.; Lappalainen, M.; Widell, A.; Asikainen, K.; Paunio, M. Hepatitis C genotypes in Finland determined by RFLP. Clin. Diagn. Virol. 1996, 7, 7-16. [CrossRef]

22. Mellor, J.; Holmes, E.C.; Jarvis, L.M.; Yap, P.L.; Simmonds, P. Investigation of the pattern of hepatitis C virus sequence diversity in different geographical regions: Implications for virus classification. The International HCV Collaborative Study Group. J. Gen. Virol. 1995, 76, 2493-2507. [CrossRef] [PubMed]

23. Kumar, S.; Stecher, G.; Li, M.; Knyaz, C.; Tamura, K. MEGA X: Molecular Evolutionary Genetics Analysis across Computing Platforms. Mol. Biol. Evol. 2018, 35, 1547-1549. [CrossRef] 
24. Yu, M.L.; Chuang, W.L.; Chen, S.C.; Dai, C.Y.; Hou, C.; Wang, J.H.; Lu, S.N.; Huang, J.F.; Lin, Z.Y.; Hsieh, M.Y.; et al. Changing prevalance of hepatitis $C$ virus genotypes: Molicular epidemiology and clinical implications in the hepatitis $C$ virus hyperendemic areas and a tertiary referral center in Taiwan. J. Med. Virol. 2001, 65, 58-65. [CrossRef]

25. Hedskog, C.; Parhy, B.; Chang, S.; Zeuzem, S.; Moreno, C.; Shafran, S.D.; Borgia, S.M.; Asselah, T.; Alric, L.; Abergel, A.; et al. Identification of 19 Novel Hepatitis C Virus Subtypes-Further Expanding HCV Classification. Open Forum Infect. Dis. 2019, 6, ofz076. [CrossRef] [PubMed]

26. Wu, J.S.; Lee, H.F.; Hsiau, H.L.; Lu, H.Y.; Chou, W.H.; Lu, C.F.; Chen, H.Y.; Lee, F.N.; Chen, P.Y.; Tam, K.M. Genotype distribution of hepatitis C virus infection in Taiwan. J. Med. Virol. 1994, 44, 74-79. [CrossRef] [PubMed]

27. Stuyver, L.; Wyseur, A.; van Arnhem, W.; Hernandez, F.; Maertens, G. Second-generation line probe assay for hepatitis C virus genotyping. J. Clin. Microbiol. 1996, 34, 2259-2266. [CrossRef] [PubMed]

28. Simmonds, P.; Bukh, J.; Combet, C.; Deleage, G.; Enomoto, N.; Feinstone, S.; Halfon, P.; Inchauspe, G.; Kuiken, C.; Maertens, G.; et al. Consensus proposals for a unified system of nomenclature of hepatitis C virus genotypes. Hepatology 2005, 42, 962-973. [CrossRef]

29. Hraber, P.T.; Fischer, W.; Bruno, W.J.; Leitner, T.; Kuiken, C. Comparative analysis of hepatitis C virus phylogenies from coding and non-coding regions: The 5' untranslated region (UTR) fails to classify subtypes. Virol. J. 2006, 3, 103. [CrossRef]

30. Murphy, D.G.; Willems, B.; Deschenes, M.; Hilzenrat, N.; Mousseau, R.; Sabbah, S. Use of sequence analysis of the NS5B region for routine genotyping of hepatitis $C$ virus with reference to $C / E 1$ and 5 ' untranslated region sequences. J. Clin. Microbiol. 2007, 45, 1102-1112. [CrossRef] [PubMed]

31. Mallory, M.A.; Lucic, D.; Ebbert, M.T.; Cloherty, G.A.; Toolsie, D.; Hillyard, D.R. Evaluation of the Abbott RealTime HCV genotype II plus RUO (PLUS) assay with reference to core and NS5B sequencing. J. Clin. Virol. 2017, 90, 26-31. [CrossRef]

32. Hsieh, M.H.; Tsai, J.J.; Hsieh, M.Y.; Huang, C.F.; Yeh, M.L.; Yang, J.F.; Chang, K.; Lin, W.R.; Lin, C.Y.; Chen, T.C.; et al. Hepatitis C virus infection among injection drug users with and without human immunodeficiency virus co-infection. PLoS ONE 2014, 9 , e94791. [CrossRef]

33. Lee, H.C.; Ko, N.Y.; Lee, N.Y.; Chang, C.M.; Ko, W.C. Seroprevalence of viral hepatitis and sexually transmitted disease among adults with recently diagnosed HIV infection in Southern Taiwan, 2000-2005: Upsurge in hepatitis C virus infections among injection drug users. J. Formos. Med. Assoc. 2008, 107, 404-411. [CrossRef]

34. Chen, Y.M.; Lan, Y.C.; Lai, S.F.; Yang, J.Y.; Tsai, S.F.; Kuo, S.H. HIV-1 CRF07_BC infections, injecting drug users, Taiwan. Emerg. Infect. Dis. 2006, 12, 703-705. [CrossRef] [PubMed]

35. Lin, H.H.; Shih, Y.L.; Liu, Y.C.; Lee, S.S.; Huang, C.K.; Chen, Y.L.; Chin, C.; Lai, C.H.; Tsai, H.C.; Guo, Y.C.; et al. An epidemic of HIV type I CRF07_BC infection among injection drug users in Taiwan. J. Acquir. Immune Defic. Syndr. 2006, 42, 248-255. [CrossRef]

36. Tee, K.K.; Pybus, O.G.; Liao, H.; Uenishi, R.; Hase, S.; Kamarulzaman, A.; Li, X.J.; Takebe, Y. Chronology of the HIV-1 CRF07_BC expansion in East Asia. AIDS 2008, 22, 156-158. [CrossRef]

37. Chen, Y.M.; Kuo, S.H. HIV-1 in Taiwan. Lancet 2007, 369, 623-625. [CrossRef]

38. Tee, K.K.; Pybus, O.G.; Li, X.J.; Han, X.; Shang, H.; Kamarulzaman, A.; Takebe, Y. Temporal and spatial dynamics of human immunodeficiency virus type 1 circulating recombinant forms 08_BC and 07_BC in Asia. J. Virol. 2008, 82, 9206-9215. [CrossRef]

39. Li, C.; Fu, Y.; Lu, L.; Ji, W.; Yu, J.; Hagedorn, C.H.; Zhang, L. Complete genomic sequences for hepatitis C virus subtypes 6e and $6 \mathrm{~g}$ isolated from Chinese patients with injection drug use and HIV-1 co-infection. J. Med. Virol. 2006, 78, 1061-1069. [CrossRef]

40. Lu, L.; Nakano, T.; Li, C.; Fu, Y.; Miller, S.; Kuiken, C.; Robertson, B.H.; Hagedorn, C.H. Hepatitis C virus complete genome sequences identified from China representing subtypes $6 \mathrm{k}$ and $6 \mathrm{n}$ and a novel, as yet unassigned subtype within genotype 6 . J. Gen. Virol. 2006, 87, 629-634. [CrossRef]

41. Tokita, H.; Okamoto, H.; Iizuka, H.; Kishimoto, J.; Tsuda, F.; Lesmana, L.A.; Miyakawa, Y.; Mayumi, M. Hepatitis C virus variants from Jakarta, Indonesia classifiable into novel genotypes in the second (2e and 2f), tenth (10a) and eleventh (11a) genetic groups. J. Gen. Virol. 1996, 77, 293-301. [CrossRef]

42. Chen, Y.; Yu, C.; Yin, X.; Guo, X.; Wu, S.; Hou, J. Hepatitis C virus genotypes and subtypes circulating in Mainland China. Emerg. Microbes Infect. 2017, 6, e95. [CrossRef] [PubMed]

43. An, Y.; Wu, T.; Wang, M.; Lu, L.; Li, C.; Zhou, Y.; Fu, Y.; Chen, G. Conservation in China of a novel group of HCV variants dating to six centuries ago. Virology 2014, 464-465, 21-25. [CrossRef] [PubMed]

44. Wu, T.; Xing, Z.; Yuan, M.; Ge, J.; Yuan, G.; Liang, K.; Wu, B.; Xiao, F.; Li, C.; Zhou, Y.; et al. Analysis of HCV Isolates Among the Li Ethnic in Hainan Island of South China Reveals Their HCV-6 Unique Evolution and a New Subtype. Cell Physiol. Biochem. 2018, 50, 1832-1839. [CrossRef]

45. Wu, T.; Xiong, L.; Wang, F.; Xu, X.; Wang, J.; Lin, F.; Li, C.; Lu, L.; Zhou, Y. A Unique Pattern of HCV Genotype Distribution on Hainan Island in China Revealed by Evolutionary Analysis. Cell Physiol. Biochem. 2016, 39, 316-330. [CrossRef]

46. Li, C.; Barnes, E.; Newton, P.N.; Fu, Y.; Vongsouvath, M.; Klenerman, P.; Okamoto, H.; Abe, K.; Pybus, O.G.; Lu, L. An expanded taxonomy of hepatitis $C$ virus genotype 6: Characterization of 22 new full-length viral genomes. Virology 2015, 476, 355-363. [CrossRef]

47. Chao, D.T.; Abe, K.; Nguyen, M.H. Systematic review: Epidemiology of hepatitis C genotype 6 and its management. Aliment. Pharmacol. Ther. 2011, 34, 286-296. [CrossRef]

48. Lu, S.N.; Su, W.W.; Yang, S.S.; Chang, T.T.; Cheng, K.S.; Wu, J.C.; Lin, H.H.; Wu, S.S.; Lee, C.M.; Changchien, C.S.; et al. Secular trends and geographic variations of hepatitis B virus and hepatitis $C$ virus-associated hepatocellular carcinoma in Taiwan. Int. J. Cancer 2006, 119, 1946-1952. [CrossRef] 